\title{
THE ASSESSMENT OF ABUTMENT SCREW STABILITY BETWEEN THE EXTERNAL AND INTERNAL HEXAGONAL JOINT UNDER CYCLIC LOADING
}

\author{
Tae-Sik Lee', DDS, MSD, Jung-Suk Han ${ }^{2 *}$, DDS, MSD, PhD, Jae-Ho Yang², DDS, MSD, PhD, \\ Jae-Bong Lee ${ }^{2}$, DDS, MSD, PhD, Sung-Hun Kim ${ }^{3}$, DDS, PhD \\ ${ }^{1}$ Graduate Student, ${ }^{2}$ Professor, ${ }^{3}$ Associate Professor, \\ Department of Prosthodontics, Graduate School, Seoul National University
}

\section{INTRODUCTION}

Since the Brånemark implant was introduced in dental therapy, many successful clinical applications have been reported. Osseointegration is no longer an issue in the success of implant treatment; $;^{1-2}$ instead, esthetic and mechanical stability in implant-supported restoration is the focus in dentistry today. ${ }^{3,4}$

The implant is not a natural tooth, so unsolved mechanical and biological problems of implant exist. ${ }^{5-7}$ To solve these problems, there have been many developments in shape, surface, materials, and surgical technique. In the current dental market, numerous types of implants are available and they are broadly divided into two groups by the type of joint between the abutment and fixture; internal and external implant/abutment connections. ${ }^{8}$

The external hexagonal connection has advantages such as suitability for a two-stage method, an anti-rotation mechanism, and retrievability and compatibility among different systems. It also has disadvantages: 1) micromovements because of the size of the hex, 2) a higher center of rotation, which leads to lower resistance for rotational and lateral movements, and 3) a micro-gap leading to bone resorption. However, the weak-link to the external hexagonal type is often referred to as a fail-selfmechanism, which prevents more severe failure in overloading situations. ${ }^{8-10}$

The internal hexagonal connection is easy to connect to the abutment without a radiograph for the fit of the joint, is suitable for a one-stage method, has higher stability and anti-rotation because of a wider area of connection and higher resistance to lateral loads because of the lower center of rotation; it also has better force distribution. ${ }^{8-10}$ Its disadvantages include a thinner lateral wall at the connecting part and difficulty in adjusting divergences in angles between fixtures.

Regardless of the kind of abutment, screw loosening has been reported as the most common factor of failure and reason for complaint in implant-supported restorations. ${ }^{11-17}$ The exact frequency of screw loosening has not been reported because this process is a result, in part, of differences in restoration designs and the large variability in biting force and habits between both people and different teeth in the same mouth. ${ }^{18-20}$

The preload is the most important factor for keeping a joint stable. It is developed in the stem of a screw when torque is applied to the screw. The screw, like a rubber band, is stretched within its head and mating thread; this makes a clamping force, which closely connects the two parts and makes a stable joint without movement. ${ }^{9,17}$

The purpose of this study is to assess the difference in abutment screw stability between the external and internal hexagonal connections under different cyclic loading conditions. This study adds to the understanding of joint stability in the two different systems under different loading cycles.

Corresponding Author: Jung-Suk Han

Department of Prosthodontics School of Dentistry, Seoul National University

28 youngun-dong, Jongno-gu, Seoul, 110-749, Korea+82 2992 7050: e-mail,proshan@unitel.co.kr

Received October 6, 2008 Last Revison December 8, 2008 Accepted December 9, 2008.

※ This work was supported by the Korea Science and Engineering Foundation (KOSEF) grant funded by The Korean government (MOST) (No. R01-2007-000-10977-0). 


\section{MATERIALS AND METHODS}

First, the samples are divided into two groups by the type of connection: the external hexagonal connection is Group A and the internal hexagonal connection is Group B. Each group is further subdivided into an a (10 samples) and b (5 samples) according to the different loading cycles: a group used $1 \times 10^{6}$, and additional $5 \times 10^{6}$ cyclic loading, and $\mathrm{b}$ group used $3 \times 10^{6}$, and additional $3 \times 10^{6}$ cyclic loading. Table I shows the groups and their components of implant fixtures and abutment.

\section{Customized metal cap and customized jig}

A customized metal cap and jig were made by ISO/DIS Standardization. The metal cap is shaped like a hemisphere in order to transfer a load to the center (Fig. 1 - 4). The loading force was applied to the hemisphere cap. The customized jig was designed to hold the implant fixture, and the distance is $3 \mathrm{~mm}$ from the implant platform to the exposed position of the fixture. The distance of $3 \mathrm{~mm}$ was

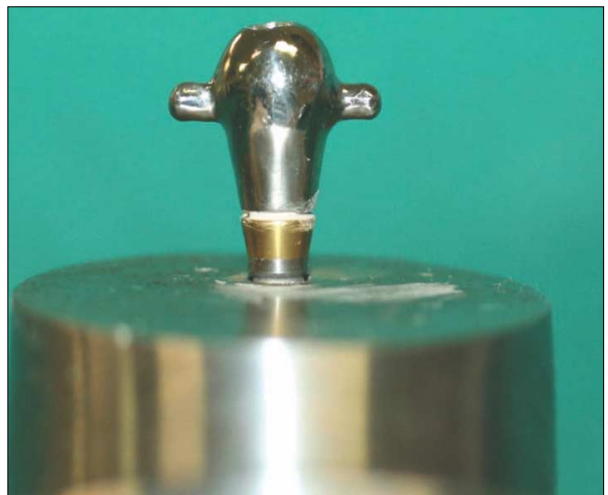

Fig. 1. The specially customized metal cap; hemisphere shape in order to transmit the applied load to the center of abutment. chosen to represent the worst case in bone retraction..$^{19}$ The load was applied on the hemispheric metal cap at $30^{\circ}$ and the distance is $11 \mathrm{~mm}$ from the center of the hemisphere to the exposed position of the fixture.

\section{Applied torque and Cyclic loading}

A total $6 \times 10^{6}$ cyclic loading was applied to the abutments using different cyclic loading durations. In subtype a group (10 samples), the removal torque value was recorded before loading, after $1 \times 10^{6}$ cyclic loading, and after additional $5 \times 10^{6}$ cyclic loading. Each removal torque value was evaluated with a digital torque gauge (Fig. 2 ), after which the abutment screw retightened to $30 \mathrm{~N} / \mathrm{cm}$ and loading cycles were resumed. In sub-type b group (5 samples), the removal the removal torque value was recorded before loading, after $3 \times 10^{6}$ cyclic loading, and after additional $3 \times 10^{6}$ cyclic loading. Procedure of evaluating the removal torque value was same to the subtype a group. Before conducting the cyclic loading, a procedure of tightening/loosening of the screw was repeated 5 times to remove micro irregularity of screw thread, and

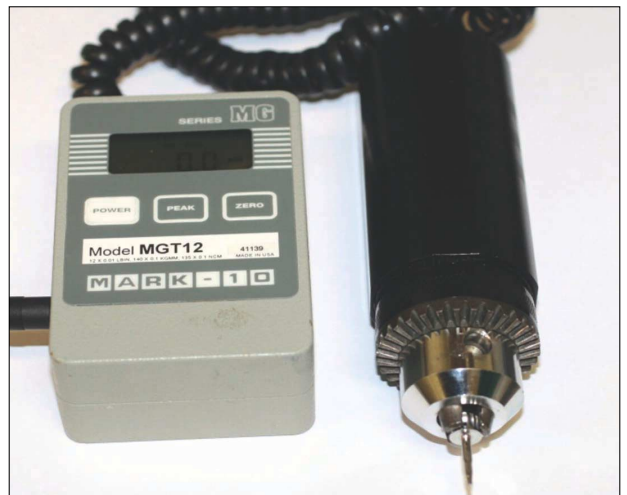

Fig. 2. Digital torque gauge (MGT12.mark-10. corp. USA). All abutment screws were tightened to $30 \mathrm{~N} / \mathrm{cm}$ $\pm 0.5 \mathrm{~N} / \mathrm{cm}$ with this digital torque gauge and the removal torque values of the screws were recorded.

Table I. Materials of tested specimens

\begin{tabular}{lll}
\hline group & Implant fixture & \multicolumn{1}{c}{ Abutment } \\
\hline Group A & implant fixtures of 4.0 $\mathrm{mm}(\varnothing) \times 11.5 \mathrm{~mm}(\mathrm{~L})$ & US cemented abutments hex regular \\
& external hexagonal connection & $5.0[\varnothing], 1.0[\mathrm{G} / \mathrm{H}], 5.5 \mathrm{~mm}[\mathrm{H}]$ \\
& (US II, OSSTEM Co., Ltd, Korea) & (GS II, OSSTEM Co., Ltd, Korea) \\
\hline Group B & implant fixtures of 4.0 $\mathrm{mm}(\varnothing) \times 11.5 \mathrm{~mm}(\mathrm{~L})$ & transfer abutment hex standard 5.0[ $\varnothing], 3.0[\mathrm{G} / \mathrm{H}]$, \\
& internal 11-degree hexagonal connection & $5.5 \mathrm{~mm}[\mathrm{H}]$, 11-degree hexagonal connection \\
& (GS II, OSSTEM Co., Ltd, Korea) & (GS II, OSSTEM Co., Ltd, Korea) \\
\hline Abutment screw & Ti-alloy : 90\% Ti, 6\% Al, 4\% Vn(OSSTEM Co., Ltd, Korea) & \\
\hline
\end{tabular}




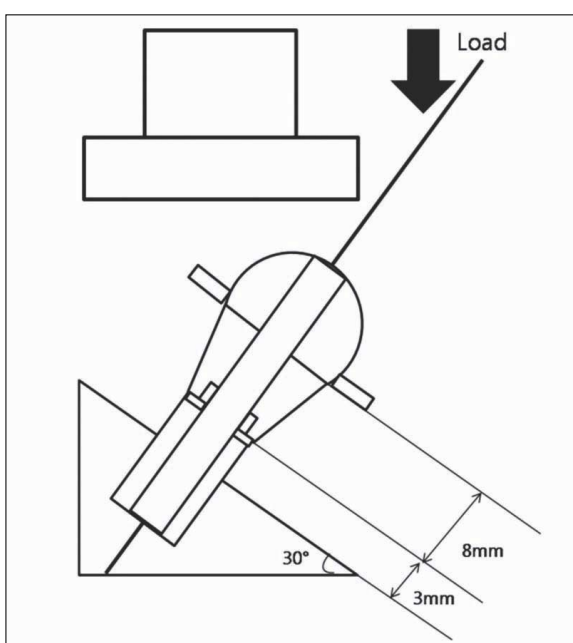

Fig. 3. Schematic diagram of the specimen. The load was applied on the hemispheric metal cap at $30^{\circ}$ and the distance was $11 \mathrm{~mm}$ from the exposed position of the fixture to the center of the hemisphere.

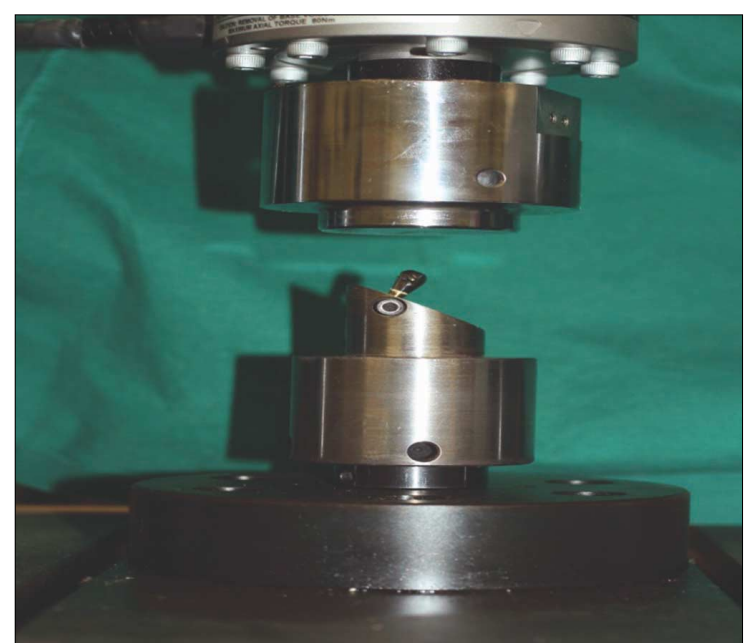

Fig. 4. The specimen is mounted in the customized jig with $30^{\circ}$ inclined plane to be loaded with load machine (Instron model 8871. USA).

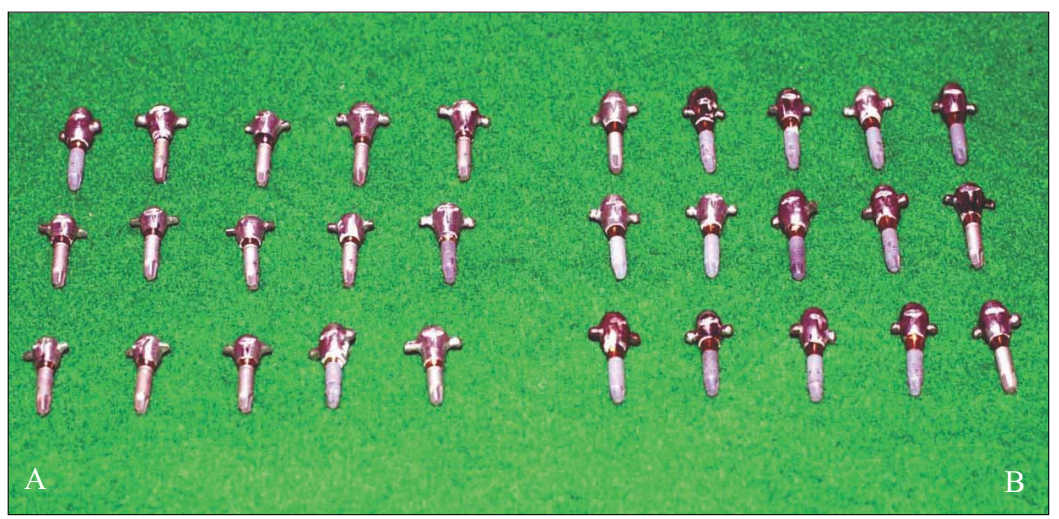

Fig. 5. Group A, B

Group A: External hexagonal connection of the abutment and fixture (Left).

Group B: Internal hexagonal connection of the abutment and fixture (Right).

then the screw was left alone for 3 minutes to recover its original state. Then, each sample is loaded in the cyclic loading machine (Instron model 8871. USA), which controls the $30-300 \mathrm{~N} / \mathrm{cm}$ cyclic loading in an Hsine shape at $14 \mathrm{~Hz}$ (Fig. 4).

\section{Statistical analysis}

SPSS statistical software for Windows (ver. 13.0, SPSS Inc., Chicago, IL, USA) was used for statistical analysis. Group means were calculated and compared by ANOVA, independent t-test, and paired t-test with $\alpha=0.05$.

\section{RESULTS}

\section{Group A (External hexagonal connection)}

In Group A-a, the mean removal torque value was 18.65 $\mathrm{N} / \mathrm{cm}$ before cyclic loading, and $19.05 \mathrm{~N} / \mathrm{cm}$ after $1 \times 10^{6}$ cyclic loading. There was no significant difference in the torque value before and after $1 \times 10^{6}$ cyclic loading (Table II). The mean removal torque value was $17.79 \mathrm{~N} / \mathrm{cm}$ after total $6 \times 10^{6}$ cyclic loading, which indicates a little loss of the preload, but it did not indicate a significant difference. In Group A-b, there was no significant difference in the removal t orque value before, after $3 \times 10^{6}$ cycles (Table II), and after additional $3 \times 10^{6}$ cyclic loading (Table II). In 
the comparison of Group A-a and Group A-b, the removal torque value was less in Group A-a $(17.79 \mathrm{~N} / \mathrm{cm})$ than in Group A-b $(18.78 \mathrm{~N} / \mathrm{cm})$ at total $6 \times 10^{6}$ cycles, but it was not significant (Table III).

\section{Group B (Internal hexagonal connection)}

In Group B-a, the mean removal torque value was 18.65 $\mathrm{N} / \mathrm{cm}$ before and $19.29 \mathrm{~N} / \mathrm{cm}$ after cyclic loading. There was no significant difference in the torque value before and after $1 \times 10^{6}$ cyclic loading (Table VI). The mean removal torque value was $11.40 \mathrm{~N} / \mathrm{cm}$ after $6 \times 10^{6}$ cyclic loading, which means a loss of the preload $(\mathrm{t}=14.096, P<.05)$ (Table VI). In Group B-b, there was no significant difference in the removal torque value before loading and after $3 \times 10^{6}$ cycles (Table VI), and after $3 \times 10^{6}$, and additional $3 \times 10^{6}$ cycles (Table VI) In the comparison of Group B-a and Group B-b, the removal torque value was less in Group B-a (11.40 N/cm) than in Group B-b (18.20 $\mathrm{N} / \mathrm{cm})$ at total $6 \times 10^{6}$ cycles, and it was significant $(\mathrm{t}=$ 10.694, $P<.05)($ Table V).

\section{Comparison of Group A and Group B}

The external hexagonal connection (Group A) was more stable than the internal hexagonal connection (Group B) after $1 \times 10^{6}$, and additional $5 \times 10^{6}$ cyclic loading $(\mathrm{t}=$ 10.834, $P<.001)$ (Table VI). There were no significant differences in the two systems after $3 \times 10^{6}$, and additional $3 \times 10^{6}$ cycles.

Table II. Assessment of the removal torque value in Group A-a and Group A-b after cyclic loading

\begin{tabular}{llccc}
\hline Group & Cyclic loading & $\begin{array}{c}\text { Mean removal } \\
\text { torque value }(\mathrm{N} / \mathrm{cm})\end{array}$ & SD & t/p value \\
\hline \multirow{3}{*}{ A-a } & Before loading & 30.16 & 0.21 & $1.801 / .080$ \\
& $1 \times 10^{6}$ & 19.05 & 1.11 & $-.793 / .433$ \\
& $1 \times 10^{6}$, and additional $5 \times 10^{6}$ & 17.79 & 1.28 & $1.664 / .104$ \\
A-b & Before loading & 30.22 & 0.19 & $1.040 / .306$ \\
& $3 \times 10^{6}$ & 19.36 & 0.64 & $-1.065 / .295$ \\
& $3 \times 10^{6}$, and additional 3 $\times 10^{6}$ & 18.78 & 0.25 & $-.197 / .845$ \\
\hline
\end{tabular}

Table III. Comparison of the removal torque value after total $6 \times 10^{6}$ cyclic loading between Group A-a and Group A-b

\begin{tabular}{llccc}
\hline Group & Cyclic loading & $\begin{array}{c}\text { Mean removal } \\
\text { torque value }(\mathrm{N} / \mathrm{cm})\end{array}$ & SD & t/p value \\
\hline A-a & $1 \times 10^{6}$, and additional $5 \times 10^{6}$ & 17.79 & 1.28 & $-1.673 / .118$ \\
A-b & $3 \times 10^{6}$, and additional $3 \times 10^{6}$ & 18.78 & 0.25 & \\
\hline
\end{tabular}

Table IV. Assessment of the removal torque value in Group B-a and Group B-b after cyclic loading

\begin{tabular}{llcrr}
\hline Group & Cyclic loading & $\begin{array}{c}\text { Mean removal } \\
\text { torque value }(\mathrm{N} / \mathrm{cm})\end{array}$ & SD & t/p value \\
\hline \multirow{3}{*}{ B-a } & Before loading & 30.32 & 0.31 & $.875 / .397$ \\
& $1 \times 10^{6}$ & 19.29 & 1.28 & $-1.239 / .223$ \\
& $1 \times 10^{6}$, and additional $5 \times 10^{6}$ & 11.40 & 1.25 & $14.096^{* * * / .000}$ \\
B-b & Before loading & 30.18 & 0.53 & $1.206 / .236$ \\
& $3 \times 10^{6}$ & 18.84 & 1.09 & $-.278 / .783$ \\
& $3 \times 10^{6}$, and additional 3 $\times 10^{6}$ & 18.20 & 0.91 & $.666 / .510$ \\
\hline
\end{tabular}

*** = significantly different $(P<.001)$

Table V . Comparison of the removal torque value after total $6 \times 10^{6}$ cyclic loading between Group A-a and Group A-b

\begin{tabular}{ccccc}
\hline Group & Cyclic loading & $\begin{array}{c}\text { Mean removal } \\
\text { torque value }(\mathrm{N} / \mathrm{cm})\end{array}$ & SD & t/p value \\
\hline B-a & $1 \times 10^{6}$, and additional $5 \times 10^{6}$ & 11.4 & 1.25 & $-10.694^{* * *} / .000$ \\
B-b & $3 \times 10^{6}$, and additional $3 \times 10^{6}$ & 18.2 & 0.91 & \\
\hline
\end{tabular}

*** = significantly different $(P<.001)$ 
Table VI. Comparison of the removal torque value after cyclic loading between Group A and Group B

\begin{tabular}{llccc}
\hline Cyclic loading & Group & $\begin{array}{c}\text { Mean removal } \\
\text { torque value (N/cm) }\end{array}$ & SD & t/p value \\
\hline $1 \times 10^{6}$ & A-a & 19.05 & 1.11 & -0.463 \\
& B-a & 19.29 & 1.28 & 1.654 \\
$1 \times 10^{6}$, and additional $5 \times 10^{6}$ & A-a & 17.79 & 1.28 & $10.834^{* * *}$ \\
& B-a & 11.40 & 1.25 & $/ .000$ \\
$3 \times 10^{6}$ & A-b & 19.36 & 0.64 & .808 \\
& B-a & 18.84 & 0.26 & 1.465 \\
$3 \times 10^{6}$, and additional 3 $\times 10^{6}$ & A-b & 18.78 & 0.91 & 1.329 \\
& B-a & 18.20 & & $/ .255$ \\
\hline
\end{tabular}

*** = significantly different $(P<.001)$

\section{DISCUSSION}

In implant prosthodontics, the stability of the joint has been shown to be a significant factor in stress transfer, biologic response of peri-implant host tissues, and screw loosening. When a screw is tightened, it is stretched between the head of screw and its thread. It has a tendency to rebound to its original state, and this creates a preload in the stem of the screw; this defines the screw tension force applied to the implant system, which creates a clamping force across the joint to prevent joint separation. ${ }^{9.17}$

The preload is influenced by several factors, such as screw material, applied torque value, screw friction, separating force of the joint, and the abutment fit.

Material properties of the screw influence the screw preload, especially the modulus of elasticity. ${ }^{20,21}$ Jörnéus et al. reported that a gold screw with a flat head with $35 \mathrm{~N} / \mathrm{cm}$ tightening torque produced the best results in conical head Ti grade 1, flat head Ti grade 1, flat head Ti grade 3, and flat head gold alloy. ${ }^{9}$ In this study, the Ti-alloyed screw (90\% Ti, $6 \% \mathrm{Al}, 4 \% \mathrm{Vn}$ : OSSTEM Co, Ltd, Korea) was used, so if a gold screw was used, the removal torque value might be higher.

In this study, for accurate preload, the tightening/loosening procedure was repeated 5 times for reducing the thread friction, which caused a reduced preload. The friction is higher at the first closing/opening of a screw cycle, making the surface irregularity smooth, but many repeated cycles cause the thread to become disengaged and deformed, so the procedure is limited to 5 times in this study. ${ }^{18-20}$ The screw was left for 3 minutes to return to its original state. The titanium abutment screw is tightened to $30 \mathrm{~N} / \mathrm{cm}$ with a digital torque gauge, which makes preload of the screw more reliable and controllable than the manual method (Fig. 2)..$^{1719}$ The manufacturer recommends the torque value for its product, which is considered its material yield strength. In the clinic, applying the correct torque on the screw is the most important factor in preventing screw loosening, so in this study, the digital torque gauge was used to tighten the screw. ${ }^{18,21}$

Friction between the screw and mating part of the implant determines how much torque force should be used during tightening to establish the preload. About $90 \%$ of the applied tightening force is lost; only $10 \%$ produces the preload, so reducing the surface texture increases the preload. After the screw is tightened, friction is important to secure the joint, and in an internal connection with an inner tapered abutment, friction between the taper interfaces contributes to joint stability. ${ }^{10,21-23}$

If a bending force caused a load larger than the yield strength of the screw, a plastic permanent deformation resulted. In both systems, the point of plastic deformation or the critical zone was noted to be at the concave neck just above the abutment thread or abutment screw thread. ${ }^{21}$ In the Astra system, the point of plastic deformation was at the neck of the bridge screw just below the screw head; whereas, for the external butt connection, it was at the concave zone above the thread of the abutment screw, because the lateral wall of the internal conical implant played a role of the dissipation of the load. ${ }^{23-26}$ In this study, no deformation of the screw was observed in external and internal connectional abutment.

The abutment fit is also a significant factor in screw loosening, stress transfer, and biologic response of periimplant tissues. Jornéus et al. reached a similar conclusion: screw joints could be made more resistant to screw 
loosening by the elimination of rotational misfit. ${ }^{9}$ In addition, Norton MR. used 8- and 11-degree internal cones (ITI and Astra) to determine the correlation between loosening and tightening torque in different taper types, but there were no significant differences. ${ }^{27}$ In this study, the 11 degree tapered internal hexagonal abutment (Group B) was used and its effect on the stability of the joint was not significant.

For many dental implants, it is known that the marginal bone will retract following implantation to a steady-level, so in this study,the distance $3 \mathrm{~mm}$ was chosen to provide a worst case with respect to bone retraction, and the cyclic loadings were applied to samples at $30^{\circ}$, which is more similar to the clinical state of anterior teeth. ${ }^{19}$

In this study, there was no effect of conical connection on screw stability (Group B); this result may be caused by the different pattern of stress distribution between the bone and this customized jig. The external hexagonal connection (Group A) was more stable than the internal hexagonal connection (Group B) after $1 \times 10^{6}$, and additional $5 \times 10^{6}$ cyclic loading $(\mathrm{t}=10.834, P<.001)$ (Table VI). There were no significant differences in the two systems after $3 \times 10^{6}$, and additional $3 \times 10^{6}$ cycles (Table VI). A long-term study may be needed to assess the screw stability in these two different connection types.

The results of the study are limited to the mechanical point of the internal and external connection implant system; in addition, there was a small number of specimens and they were only tested under dry conditions. As biologic conditions such as saliva, heat, and corrosion may affect the abutment-implant interface, further research is needed to increase the understanding of the characteristics of this interface.

\section{CONCLUSION}

Abutment screw stability between an external and internal hexagonal connection was assessed under cyclic loading. From this study, the following may be concluded.

1. There was no significant difference in the removal torque values after $1 \times 10^{6}$ cyclic loading, after $3 \times$ $10^{6}$ cyclic loading, and after $3 \times 10^{6}$, and additional 3 $\times 10^{6}$ cyclic loading, respectively, between the external hexagonal connection and the internal hexagonal connection.

2. In the internal hexagonal connection, compared to the removal torque value of the abutment screw at $1 \times 10^{6}$ cyclic loading, the value after $1 \times 10^{6}$, and additional 5 $\times 10^{6}$ cyclic loading was reduced and the difference was significant $(P<.001)$ (Table $V)$.

3. The external hexagonal connection (Group A) was more stable than the internal hexagonal connection (Group B) after $1 \times 10^{6}$, and additional $5 \times 10^{6}$ cyclic loading $(\mathrm{t}=10.834, P<.001)($ Table VI).

4. After $3 \times 10^{6}$, and additional $3 \times 10^{6}$ cyclic loading situation, the difference of the removal torque value of the abutment screw between the external hexagonal connection and the internal hexagonal connection was not significant (Table VI).

\section{REFERENCES}

1. Brånemark PI, Hansson BO, Adell R, Breine U, Lindstrom $\mathrm{J}$, Hallén O, Ohman A. Osseointegrated implants in the treatment of the edentulous jaw. Experience from a 10-year period. Scand J Plast Reconstr Surg Suppl 1977;16:1-132.

2. Adell R, Lekholm U, Rockler B, Branemark PI. A 15-year study of osseointegrated implants in the treatment of the edentulous jaw. Int J Oral Surg 1981;10:387-416.

3. Jemt T, Lekholm U. Oral implant treatment in posterior partially edentulous jaws: a 5-year follow-up report. Int J Oral Maxillofac Implants 1993;8:635-40.

4. Nevins M, Langer B. The successful application of osseointegrated implants to the posterior jaw: a long-term retrospective study. Int J Oral Maxillofac Implants 1993;8:428-32.

5. Sones AD. Complications with osseointegrated implants. J Prosthet Dent 1989;62:581-5.

6. Zarb GA, Schmitt A. The longitudinal clinical effectiveness of osseointegrated dental implants: the Toronto study. Part III: Problems and complications encountered. J Prosthet Dent 1990;64:185-94.

7. Jemt $\mathrm{T}$, Lindén B, Lekholm U. Failures and complications in 127 consecutively placed fixed partial prostheses supported by Branemark implants: from prosthetic treatment to first annual checkup. Int J Oral Maxillofac Implants 1992;7:40-4.

8. Maeda Y, Satoh T, Sogo M. In vitro differences of stress concentrations for internal and external hex implant-abutment connections: a short communication. J Oral Rehabil 2006;33:75-8.

9. Jornéus L, Jemt T, Carlsson L. Loads and designs of screw 
joints for single crowns supported by osseointegrated implants. Int J Oral Maxillofac Implants 1992;7:353-9.

10. Binon PP. The effect of implant/abutment hexagonal misfit on screw joint stability. Int J Prosthodont 1996;9:149-60.

11. Worthington P, Bolender CL, Taylor TD. The Swedish system of osseointegrated implants: problems and complications encountered during a 4-year trial period. Int J Oral Maxillofac Implants 1987;2:77-84.

12. Zarb GA, Schmitt A. The longitudinal clinical effectiveness of osseointegrated dental implants: the Toronto study. Part III: Problems and complications encountered. J Prosthet Dent 1990;64:185-94.

13. Hemmings KW, Schmitt A, Zarb GA. Complications and maintenance requirements for fixed prostheses and overdentures in the edentulous mandible: a 5-year report. Int $\mathrm{J}$ Oral Maxillofac Implants 1994;9:191-6.

14. Kallus T, Bessing C. Loose gold screws frequently occur in full-arch fixed prostheses supported by osseointegrated implants after 5 years. Int J Oral Maxillofac Implants 1994:9:169-78.

15. Jemt $\mathrm{T}$. Fixed implant-supported prostheses in the edentulous maxilla. A five year follow-up report. Clin Oral Implants Res 1994;5:142-7.

16. Schwartz-Arad D, Samet N, Samet N. Single tooth replacement of missing molars: a retrospective study of 78 implants. J Periodontol 1999;70:449-54.

17. Binon PP. The external hexagonal interface and screw-joint stability: a primer on threaded fasteners. Quintessence Dent Technol 2000;23:91-105.

18. Haack JE, Sakaguchi RL, Sun T, Coffey JP. Elongation and preload stress in dental implant abutment screws. Int J Oral Maxillofac Implants 1995;10;529-36.
19. ISO/DIS 14801: Dental implants-Dynamic continuous fatigue test. 2003.

20. Haack JE, Sakaguchi RL, Sun T, Coffey JP. Determination of preload stress in dental implant screws. J Dent Res 1994;73:202.

21. Yousef H, Luke A, Ricci J, Weiner S. Analysis of changes in implant screws subject to occlusal loading: a preliminary analysis. Implant Dent 2005;14:378-82.

22. Norton MR. An in vitro evaluation of the strength of an internal conical interface compared to a butt joint interface in implant design. Clin Oral Implants Res 1997;8:290-8.

23. Bahat $\mathrm{O}$, Handelsman $\mathrm{M}$. Use of wide implants and double implants in the posterior jaw: a clinical report. Int J Oral Maxillofac Implants 1996;11:379-86.

24. Arvidson K, Bystedt H, Frykholm A, von Konow L, Lothigius E. A 3-year clinical study of Astra dental implants in the treatment of edentulous mandibles. Int J Oral Maxillofac Implants 1992;7:321-9.

25. Vigolo P, Fonzi F, Majzoub Z, Cordioli G. An in vitro evaluation of ZiReal abutments with hexagonal connection: in original state and following abutment preparation. Int $\mathrm{J}$ Oral Maxillofac Implants 2005;20:108-14.

26. Vigolo P, Fonzi F, Majzoub Z, Cordioli G. Evaluation of gold-machined UCLA-type abutments and $\mathrm{CAD} / \mathrm{CAM}$ titanium abutments with hexagonal external connection and with internal connection. Int J Oral Maxillofac Implants 2008;23:247-52.

27. Norton MR. Assessment of cold welding properties of the internal conical interface of two commercially available implant systems. J Prosthet Dent 1999;81:159-66. 


\title{
THE ASSESSMENT OF ABUTMENT SCREW STABILITY BETWEEN THE EXTERNAL AND INTERNAL HEXAGONAL JOINT UNDER CYCLIC LOADING
}

\author{
Tae-Sik Lee', DDS, MSD, Jung-Suk Han ${ }^{2 *}$, DDS, MSD, PhD, Jae-Ho Yang², DDS, MSD, PhD, \\ Jae-Bong Lee ${ }^{2}$, DDS, MSD, PhD, Sung-Hun Kim ${ }^{3}$, DDS, PhD \\ ${ }^{1}$ Graduate Student, ${ }^{2}$ Professor, ${ }^{3}$ Associate Professor, \\ Department of Prosthodontics, Graduate School, Seoul National University
}

STATEMENT OF PROBLEM: Currently, many implant systems are developed and divided into two types according to their joint connection: external or internal connection. Regardless of the connection type, screw loosening is the biggest problem in implant-supported restoration. PURPOSE: The purpose of this study is to assess the difference in stability of abutment screws between the external and internal hexagonal connection types under cyclic loading. MATERIAL AND METHODS: Each of the 15 samples of external implants and internal abutments were tightened to $30 \mathrm{~N} / \mathrm{cm}$ with a digital torque gauge, and cemented with a hemispherical metal cap. Each unit was then mounted in a $30^{\circ}$ inclined jig. Then each group was divided into 2 sub-groups based on different periods of cyclic loading with the loading machine $\left(30 \mathrm{~N} / \mathrm{cm}-300 \mathrm{~N} / \mathrm{cm}, 14 \mathrm{~Hz}\right.$ : first group $1 \times 10^{6}, 5 \times 10^{6}$ cyclic loading; second group $3 \times 10^{6}, 3 \times 10^{6}$ for a total cyclic loading of $6 \times 10^{6}$ ) The removal torque value of the screw before and after cyclic loading was checked. SPSS statistical software for Windows was used for statistical analysis. Group means were calculated and compared by ANOVA, independent t-test, and paired t-test with $\alpha=$ 0.05. RESULTS: In the external hexagonal connection, the difference between the removal torque value of the abutment screw before loading, the value after $1 \times 10^{6}$ cyclic loading, and the value after $1 \times 10^{6}$, and additional $5 \times 10^{6}$ cyclic loading was not significant. The difference between the removal torque value after $3 \times 10^{6}$ cyclic loading and after $3 \times 10^{6}$, and additional $3 \times 10^{6}$ cyclic loading was not significant. In the internal hexagonal connection, the difference between the removal torque value before loading and the value after $1 \times$ 106 cyclic loading was not significant, but the value after $1 \times 10^{6}$, and additional $5 \times 10^{6}$ cyclic loading was reduced and the difference was significant $(P<.05)$. In addition, in the internal hexagonal connection, the difference between the removal torque value after $3 \times 10^{6}$ cyclic loading and the value after $3 \times 10^{6}$, and additional $3 \times 10^{6}$ cyclic loading was not significant. CONCLUSION: The external hexagonal connection was more stable than the internal hexagonal connection after $1 \times 10^{6}$, and additional $5 \times 10^{6}$ cyclic loading $(\mathrm{t}=10.834, P$ $<.001$ ). There was no significant difference between the two systems after $3 \times 10^{6}$, and additional $3 \times 10^{6}$ cycles.

KEY WORDS: Screw loosening, External hexagonal connection, Internal hexagonal connection, Cyclic loading

Corresponding Author: Jung-Suk Han

Department of Prosthodontics School of Dentistry, Seoul National University

28 youngun-dong, Jongno-gu, Seoul, 110-749,Korea+822992 7050: e-mail,proshan@unitel.co.kr

Article history

Received October 6, 2008 Last Revison December 8, 2008 Accepted December 9, 2008. 